\title{
Sulfitos: importância na indústria alimentícia e seus possíveis malefícios à população
}

\author{
Diego Matos Favero ${ }^{1}$, Cilene da Silva Gomes Ribeiro ${ }^{2}$, Arislete Dantas de Aquino ${ }^{3}$
}

A adição de aditivos é uma prática comum utilizada na conservação de alimentos. Os sulfitos, que incluem o dióxido de enxofre $\left(\mathrm{SO}_{2}\right)$ e seus sais de sódio, potássio e cálcio $(\mathrm{Na}, \mathrm{K}$ e $\mathrm{Ca})$, são amplamente utilizados devido ao efeito inibitório sobre bactérias, bolores e leveduras e na inibição de reações de escurecimento enzimático e não enzimático durante processamento e estocagem. O uso desses conservantes deve ser monitorado para evitar que o consumo não ultrapasse a Ingestão Diária Aceitável (IDA - 0,7 mg/ $\mathrm{kg}$ peso corpóreo). Apesar de sua eficácia, inúmeras reações adversas têm sido relatadas à saúde de algumas pessoas sensíveis aos sulfitos, como na forma de ataques asmáticos e urticária, dessa forma torna-se necessário o controle e informação dos agentes sulfitantes adicionados aos alimentos, bem como pesquisas que visem à substituição desse aditivo, por equivalentes que não prejudiquem a saúde humana.

Palavras-chave: sulfitos, aditivos, reações adversas, Ingestão Diária Aceitável (IDA).

\section{Sulfites: importance in the food industry and possible harms for the population}

The use of food additives is a regular practice for preserving foods. Sulfites are a class of food additives that include sulfur dioxide $\left(\mathrm{SO}_{2}\right)$ and its sodium, potassium and calcium $(\mathrm{Na}, \mathrm{K}$ and $\mathrm{Ca}$ ) salts. These compounds are widely added to foods due to their inhibitory effect on bacteria, molds, yeasts, enzymatic and non-enzymatic browning reactions during processing and storage. There is a Recommended Daily Intake (RDI) for sulfites, which is about $0.7 \mathrm{mg} / \mathrm{kg}$ of body mass. Thus, their addition to food must be carefully controlled. Despite its effectiveness as food preservative, many adverse reactions to the health of sensitive individuals have been reported, such as asthma attacks and urticaria. Thus, it is necessary to control and declare the sulfiting agents added to foods, and carry out research aiming at replacing sulfites as additives that are not harmful to health.

Key-words: sulfites, adverse reactions, Recommended Daily Intake.

\footnotetext{
${ }^{1}$ Mestrando do Programa de Pós Graduação em Tecnologia de Alimentos, Universidade Federal do Paraná (UFPR), Curitiba, PR. Correspondência: Caixa Postal 19011, CEP 81531-980, Curitiba, PR. E-mail: diegofavero@ig.com.br.

${ }^{2}$ Doutoranda em História e Cultura da Alimentação, Universidade Federal do Paraná (UFPR). Docente do Centro de Ciências Biológicas e da Saúde, Pontifícia Universidade Católica do Paraná (PUCPR), Curitiba, PR.

${ }^{3}$ Dra. em Engenharia Química, Universidade Estadual de Campinas (UNICAMP). Profa. Adjunta do Departamento de Engenharia Química, Universidade Federal do Paraná (UFPR), Curitiba, PR.
} 


\section{INTRODUÇÃO}

Nas últimas décadas houve uma mudança no hábito alimentar da população brasileira. Esta tem substituído parcialmente os alimentos in natura por alimentos processados. A tecnologia aplicada pela indústria de alimentos com o intuito de aumentar o tempo de vida útil desses produtos tem gerado questionamentos quanto à segurança do emprego de alguns aditivos alimentares, como por exemplo, os sulfitos ${ }^{[1]}$.

Os agentes sulfitantes - que incluem o dióxido de enxofre $\left(\mathrm{SO}_{2}\right)$ e seus sais de sódio, potássio e cálcio - são aditivos alimentares que atuam na inibição da deterioração provocada por bactérias, bolores e leveduras em alimentos ácidos, e na inibição de reações de escurecimento enzimático e não enzimático durante processamento e estocagem [2-10]. O Brasil, assim como outros países, segue as recomendações do Joint Expert Committee on Food Additives (JECFA) na utilização segura dos aditivos em alimentos e bebidas ${ }^{[11]}$.

Embora os sulfitos sejam utilizados amplamente na indústria de alimentos, o emprego deste aditivo como conservante acarreta alguns problemas, como a redução da biodisponibilidade de algumas vitaminas como a tiamina $\left(\mathrm{B}_{1}\right)$, ácido fólico $\left(\mathrm{B}_{9}\right)$, piridoxina, nicotinamida, reduzindo a qualidade nutricional dos alimentos tratados [3,8,10,12]. Além disso, a ingestão desses aditivos tem sido associada a reações adversas em algumas pessoas, tais como broncoespasmos em indivíduos asmáticos sensíveis [3,4,8,9,13]. Sérios distúrbios neurológicos também foram diagnosticados em uma pequena parcela da população com reduzida atividade da enzima sulfito oxidase, responsável pela conversão de sulfito a sulfato, este último, inócuo e rapidamente excretado pelo organismo [7,14].

É importante ressaltar que a quantidade de sulfitos adicionada aos alimentos não reflete os teores remanescentes no momento do consumo do produto, devido a perdas que podem ocorrer durante $\mathrm{o}$ processamento e estocagem e que alguns alimentos são consumidos em excesso por algumas pessoas. Dessa forma é importante avaliar a quantidade de sulfitos adicionados aos alimentos e sua ingestão diária pelos consumidores. No Brasil, o Ministério da Saúde (MS), por meio da Agência Nacional de Vigilância Sanitária (ANVISA), é responsável pela regulamentação dos aditivos alimentares ${ }^{[15]}$.
Sendo a inocuidade uma das bases na produção de alimentos, a problemática deste trabalho está em tentar esclarecer, com base em estudos científicos publicados, se há relação entre as reações de intolerância alimentar, sofridas por uma parcela da população, e o uso dos agentes sulfitantes em alimentos. Para isso, é importante informar ao leitor quais são as funções dos sulfitos na indústria de alimentos, e em quais destes, bem como a quantidade, podem estar presente.

REGULAMENTAÇÃO RECOMENDAÇÕES DO EMPREGO DE ADITIVOS NO BRASIL

O emprego de aditivos em alimentos está regulamentado no Brasil desde 1965, por meio do Decreto no 55.871. A Resolução do Conselho Nacional de Saúde (CNS), do MS, no 04/88 [16] revisa as tabelas anexas a esse Decreto. Desde então, foram elaboradas diversas atualizações na legislação brasileira, como autorizações para extensão de uso e inclusão de aditivos.

Conforme a Portaria no 540 - Secretaria de Vigilância em Saúde (SVS/MS), de 27 de outubro de 1997, aditivo alimentar é qualquer ingrediente adicionado intencionalmente aos alimentos, sem propósito de nutrir, com o objetivo de modificar as características físicas, químicas, biológicas ou sensoriais, durante a fabricação, processamento, preparação, tratamento, embalagem, acondicionamento, armazenagem, transporte ou manipulação de um alimento. Ao agregar-se poderá resultar em que o próprio aditivo ou seus derivados se convertam em um componente de tal alimento. Esta definição não inclui os contaminantes ou substâncias nutritivas que sejam incorporadas ao alimento para manter ou melhorar suas propriedades nutricionais ${ }^{[1]}$.

No Brasil, cabe ao MS, em particular à Comissão Permanente de Aditivos para Alimentos (considerar também o Grupo de Trabalho de Aditivos definido pela Portaria MS no 1007/98), estabelecer a legislação nacional para esse assunto. Tomando como base o resultado de pesquisas internacionais e as recomendações do Codex Committee on Food Additives and Contaminants (CCFAC) do JECFA, a Comissão define e fiscaliza o emprego de aditivos pela indústria nacional. Os aditivos podem ser classificados em diretos, quando são adicionados ao alimento com um propósito específico. Muitos deles são identificados no rótulo dos produtos. Os aditivos indiretos, normalmente, 
convertem-se em parte do alimento, mesmo em quantidades insignificantes [2].

Segundo a Portaria SVS/MS no 540/97 [11], deve-se observar a restrição ao uso dos aditivos. O uso dos mesmos deve ser limitado a alimentos específicos, em condições específicas e ao menor nível para alcançar o efeito desejado. Da mesma forma, a necessidade tecnológica do uso de um aditivo deve ser justificada sempre que proporcionar vantagens de ordem tecnológica e não quando puderem ser alcançadas por operações de fabricação mais adequadas ou por maiores precauções de ordem higiênica ou operacional.

Já o emprego de aditivos justifica-se por razões tecnológicas, sanitárias, nutricionais ou sensoriais sempre que forem utilizados aditivos autorizados em concentrações tais que sua ingestão diária não supere os valores de Ingestão Diária Aceitável (IDA) recomendados, da mesma forma devem atender as exigências de pureza estabelecidas pela Food and Agriculture Organization (FAO) e World Health Organization (WHO) ou pelo Food Chemicals Codex [11].

O uso de aditivos é proibido quando: houver evidências ou suspeita de que eles não sejam seguros para consumo humano; interferir sensível e desfavoravelmente no valor nutritivo do alimento; servir para encobrir falhas no processamento e/ou nas técnicas de manipulação; encobrir alteração ou adulteração da matéria-prima ou do produto já elaborado ou quando induzir o consumidor a erro, engano ou confusão [11].

A adição direta de dióxido de enxofre ou indiretamente de sais de sulfito que o produzam, como o sulfito de sódio, bissulfito de sódio, bissulfito de potássio, metabissulfito de sódio e metabissulfito de potássio, como branqueador e conservador de alimentos é permitida pelo MS [16] e aceitos como Geralmente Reconhecidos como Seguros (GRAS) pela Food and Drug Administration (FDA) [8].

Os alimentos em que os agentes sulfitantes podem ser adicionados com a função de conservadores e seus respectivos limites máximos são mostrados na Tabela 1, de acordo com a legislação brasileira vigente, sendo citado por Machado \& Toledo [3].

De modo a estabelecer um sistema numérico internacional de identificação dos aditivos alimentares como forma de declarar o mesmo nas embalagens, ao invés do nome específico do alimento, o Comitê do
Codex Alimentarius (FAO/WHO) elaborou o Sistema Internacional de Numeração de Aditivos Alimentares (INS - International Numbering System) [13]. Na Tabela 2, encontra-se a numeração (INS) dos agentes sulfitantes, bem como sua fórmula química e o rendimento teórico de $\mathrm{SO}_{2}$ de cada componente.

\section{UTILIZAÇÃO E FUNÇÕES DOS AGENTES SULFITANTES NA INDÚSTRIA DE ALIMENTOS}

Além da preocupação com as características sensoriais do alimento produzido, a indústria alimentícia visa à produção de alimentos estáveis e seguros para o consumidor, que tenham uma longa vida de prateleira. Uma das técnicas utilizadas, como já citado, é a adição de conservantes em seu processo de beneficiamento, como por exemplo, os sulfitos [6,8]. Estes são agentes multifuncionais, com capacidade de prevenir em alimentos o escurecimento enzimático e não enzimático, controlar o desenvolvimento microbiológico, atuar como agente branqueador, antioxidante ou redutor [2- 9,17]. Devido a essas múltiplas funções, os sulfitos são usados em vários produtos como frutas desidratadas, vinhos, sucos industrializados [2,3,10,13], bebidas carbonatadas, que contenham suco de fruta [18], biscoitos, geleias e mostarda [10], hortaliças desidratadas (com exceção da cebola e do alho) [2,10], frutas e legumes frescos, licores, produtos cárneos como salsichas, peixes e linguiças [2].

\section{Antimicrobianos}

Os sulfitos são antimicrobianos com efeito inibitório sobre bactérias e leveduras, sendo que sua atividade antimicrobiana é dependente de sua forma química, sendo mais pronunciada em valores de $\mathrm{pH}$ inferiores a 3 , devido à maior liberação de dióxido de enxofre molecular [3]. Para o gás $\mathrm{SO}_{2}$ dissolvido, três estados de dissociação coexistem no equilibrio: o ácido sulfuroso indissociável $\mathrm{SO}_{2} \mathrm{H}_{2} \mathrm{O}, \quad$ o sulfito de hidrogênio $\mathrm{HSO}_{3}-$ e os íons sulfito $\mathrm{SO}_{3}{ }^{2-}$. Para valores de $\mathrm{pH}$ de aproximadamente 1,7, o conteúdo de ácido sulfuroso indissociável é predominante. $\mathrm{Na}$ faixa de $\mathrm{pH}$ de 1,7 a 5,1 a maior quantidade deve-se aos íons sulfito de hidrogênio, enquanto acima do pH 5,1 a maior parte do ácido sulfuroso está dissociado [4,19]. As proporções das diversas fases de dissociação estão relatadas na Figura 1.

De acordo com a literatura consultada, a ação antimicrobiana do dióxido de enxofre baseia-se em dois princípios. O primeiro refere-se à inibição, pelos 
Tabela 1. Limites máximos dos agentes sulfitantes em alimentos [3].

\begin{tabular}{|c|c|}
\hline Alimentos & $\begin{array}{c}\text { Limite máximo } \\
(\mathrm{g} / 100 \mathrm{~g} ; \mathrm{g} / 100 \mathrm{~mL}- \\
\left.\text { expresso em } \mathrm{SO}_{2} \text { residual }\right)\end{array}$ \\
\hline Açúcar refinado & 0,002 \\
\hline Batata descascada cozida (somente metabissulfito de sódio) & 0,01 \\
\hline Batatas fritas congeladas & 0,01 \\
\hline Bebidas alcoólicas fermentadas & 0,01 \\
\hline Bebidas alcoólicas mistas & 0,01 \\
\hline Bebidas não alcoólicas à base de soja & 0,004 \\
\hline Bebidas não alcoólicas gaseificadas e não gaseificadas* & 0,004 \\
\hline Camarões e lagostas (exclusivamente na matéria-prima após a captura) - Cozido & 0,003 \\
\hline Camarões e lagostas (exclusivamente na matéria-prima após a captura) - Cru & 0,01 \\
\hline Cervejas (somente ditionito) & 0,006 \\
\hline Coco ralado & 0,02 \\
\hline Cogumelos & 0,005 \\
\hline Cooler & 0,035 \\
\hline Filtrado doce & 0,035 \\
\hline Frutas dessecadas & 0,01 \\
\hline Frutose & 0,002 \\
\hline Geleias artificiais & 0,02 \\
\hline Jeropiga & 0,01 \\
\hline Legumes e verduras desidratadas & 0,02 \\
\hline Leite de coco esterilizado & 0,01 \\
\hline Leite de coco pasteurizado & 0,03 \\
\hline Licores de frutas & 0,01 \\
\hline Mistela composta & 0,025 \\
\hline Néctares de frutas & 0,02 \\
\hline Passas de frutas & 0,15 \\
\hline Picles & 0,01 \\
\hline Polpas de vegetais** & 0,03 \\
\hline Purê de vegetais** & 0,06 \\
\hline Raiz Forte (polpa de rábano ou wasabi) (somente metabissulfito de sódio)*** & 0,05 \\
\hline Sangria & 0,035 \\
\hline Saquê & 0,035 \\
\hline Sidras & 0,035 \\
\hline Suco de caju*** & 0,0333 \\
\hline Suco de caju alto teor de polpa (diluição 1:9) & 0,30 \\
\hline Sucos de frutas & 0,02 \\
\hline Vinagres & 0,02 \\
\hline Vinhos & 0,035 \\
\hline Vinhos compostos & 0,025 \\
\hline Vinhos de frutas & 0,035 \\
\hline Xarope de glicose & 0,004 \\
\hline
\end{tabular}

* Prontas para o consumo e preparados líquidos; ** incluindo cogumelos, fungos, legumes, hortaliças, raízes e tubérculos, castanhas e algas marinhas; *** no produto a ser consumido. 
Tabela 2. Identificação internacional dos agentes sulfitantes [3,4].

\begin{tabular}{lccc}
\hline \multicolumn{1}{c}{ Substância } & Fórmula química & Rendimento teórico de $\mathrm{SO}_{2}(\%)$ & INS \\
\hline Dióxido de enxofre & $\mathrm{SO}_{2}$ & 100,0 & 220 \\
Sulfito de sódio & $\mathrm{Na}_{2} \mathrm{SO}_{3}$ (anidro) & 50,8 & 221 \\
Bissulfito de sódio & $\mathrm{NaHSO}_{3}$ & 61,6 & 222 \\
Metabissulfito de sódio & $\mathrm{Na}_{2} \mathrm{~S}_{2} \mathrm{O}_{5}$ & 67,4 & 223 \\
Metabissulfito de potássio & $\mathrm{K}_{2} \mathrm{~S}_{2} \mathrm{O}_{5}$ & 57,6 & 224 \\
Sulfito de potássio & $\mathrm{K}_{2} \mathrm{SO}_{3}$ & $*$ & 225 \\
Sulfito de cálcio & $\mathrm{CaSO}_{3} \cdot 2 \mathrm{H}_{2} \mathrm{O}$ & 64,0 & 226 \\
Bissulfito de cálcio & $\mathrm{Ca}_{\left(\mathrm{HSO}_{3}\right)_{2}}$ & $*$ & 227 \\
Bissulfito de potássio & $\mathrm{KHSO}_{3}$ & 53,3 & 228 \\
\hline
\end{tabular}

INS - International Numbering System (Sistema Internacional de Numeração).

* não foi encontrado na literatura.

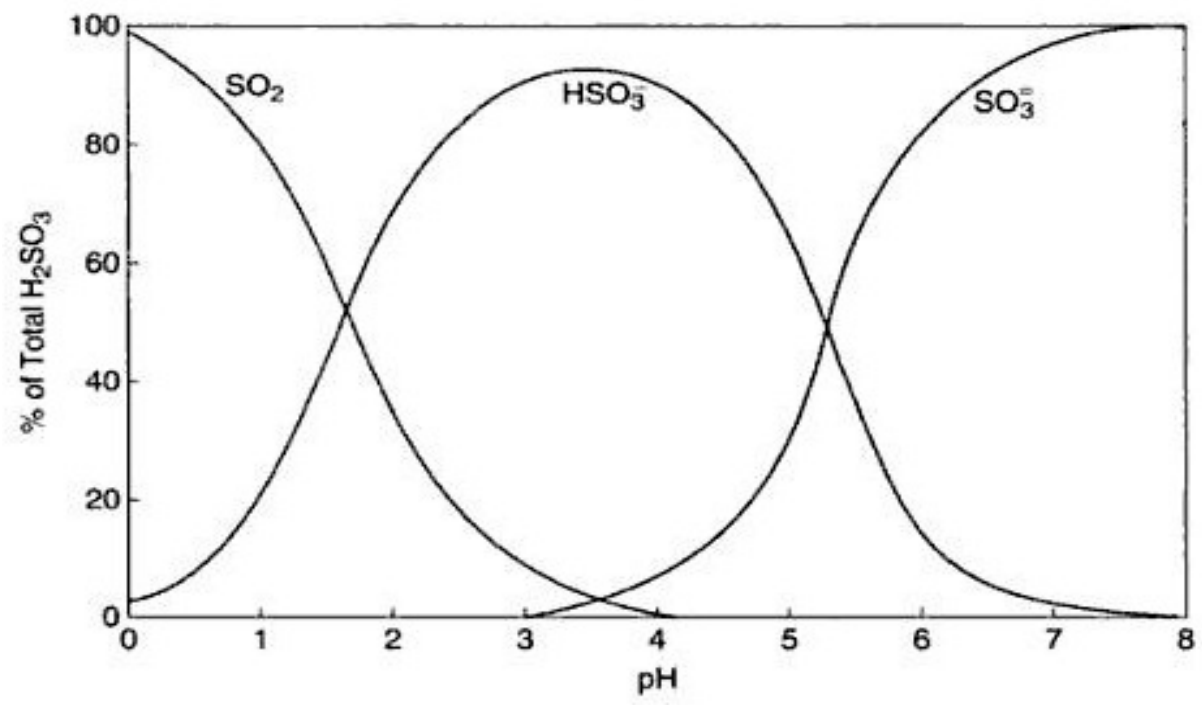

Figura 1. Proporção de dióxido de enxofre $\left(\mathrm{SO}_{2}\right)$, sulfito de hidrogêncio $\left(\mathrm{HSO}_{3}{ }^{-}\right)$ e íons sulfitos $\left(\mathrm{SO}_{3^{2}}{ }^{2}\right)$ em soluções aquosas em função do $\mathrm{pH}{ }^{[19]}$.

sulfitos, de reações catalisadas enzimaticamente, dependendo assim da penetração do $\mathrm{SO}_{2}$ molecular através da membrana celular do microrganismo. Os alvos mais prováveis para a inibição de microrganismos por sulfitos incluem a ruptura da membrana citoplasmática, inativação da replicação do DNA, síntese de proteínas, inativação de enzimas vinculadas à membrana citoplasmática, ou reações individuais com os componentes de vias metabólicas. Danos celulares podem resultar da interação dos sulfitos com os grupos SH de proteínas estruturais e interações com enzimas, cofatores, vitaminas, ácidos nucléicos e lipídios. A sensibilidade das enzimas com grupos SH é o principal efeito inibitório contra as reações NAD-dependentes, 
como por exemplo, a inibição da formação do oxaloacetato a partir do malato, efeito esse responsável pela inibição da Escherichia coli [4,9]. No caso das leveduras, outra característica observada é o bloqueio da fase de reação do gliceraldeído-3-fosfato a 1,3-di-Pglicerato [4,14].

O segundo princípio da ação antimicrobiana, principalmente em microrganismos aeróbios, é o alto poder redutor dos agentes sulfitantes, que causa uma diminuição no nível de oxigênio, sendo inviável o crescimento destes microrganismos [4]. Todavia, aqueles microrganismos aeróbios que possuem capacidade de serem também anaeróbicos facultativos (geralmente todos os microrganismos patogênicos são anaeróbicos facultativos) e os anaeróbicos, são favorecidos com esta modificação ${ }^{[8]}$.

A ligação de sulfitos com componentes dos alimentos tais como aldeídos, cetonas, glicídios e taninos, afetam a sua atividade porque os adutos hidroxisulfonados não apresentam ação antimicrobiana. Os sulfitos que não se ligam a outras moléculas são chamados de "sulfitos livres" e correspondem a uma mistura de $\mathrm{SO}_{2}$, íon bissulfito ( $\mathrm{HSO}_{3}^{-}$) e íon sulfito $\left(\mathrm{SO}_{3}{ }^{2-}\right)$ em equilibrio químico dinâmico. Em certas condições, uma porção das moléculas de sulfitos ligados, chamada ligação sulfito reversível, dissocia-se e forma os sulfitos livres [3,7].

O metabissulfito de sódio é uma substância química utilizada na indústria como alvejante, desinfetante e antioxidante. Este produto funciona como agente inibidor do oxigênio molecular $\left(\mathrm{O}_{2}\right)$, impedindo que o alimento seja oxidado por bactérias aeróbias. Seu resíduo é o dióxido de enxofre $\left(\mathrm{SO}_{2}\right)$ (Figura 2), que não se constitui como fator prejudicial à saúde dos consumidores, quando sua concentração encontra-se numa faixa de 40 a 100 ppm (partes por milhão), segundo a Organização Mundial da Saúde [8].

$$
\mathrm{O}=\mathrm{S} \rightarrow \mathrm{O}
$$

Dióxido de enxofre Metabissulfito de Sódio

Figura 2. Estrutura molecular do dióxido de enxofre e metabissulfito de sódio [7].

\section{Inibidores do escurecimento enzimático e não enzimático}

Frutas e hortaliças, além de altamente nutritivas, são atrativas devido à variedade de pigmentos que contêm e, assim, a cor é um critério importante na decisão de compra pelo consumidor. As mudanças de cor em frutas e hortaliças possuem diferentes origens, podendo ser influenciadas pela presença de pigmentos naturais, como clorofilas, carotenóides e antocianinas ou por pigmentos formados em reações enzimáticas (Polifenoloxidase PFO) e não enzimáticas (Reação de Maillard) ${ }^{[5,20] . ~}$

O escurecimento enzimático ocorre, devido principalmente, à presença da enzima PFO (PFO; EC 1.10.3.1), também utilizada como um termo genérico para designar um grupo de enzimas que catalisam a oxidação de compostos fenólicos, como por exemplo, ascorbato oxidase, lipoxigenase, peroxidase e enzimas dependentes de tiamina, produzindo pigmentos escuros em cortes ou superfícies danificadas de frutas e hortaliças. Quando o tecido é danificado pelo corte, a enzima entra em contato com seu substrato e a formação de pigmentos escuros ocorre favorecida pela exposição ao oxigênio [3,5,21]. A principal via de escurecimento enzimático inicia-se com a oxidação de fenóis endógenos por ação da enzima PFO na presença de oxigênio formando o-quinona e a subsequente polimerização destas, num mecanismo complexo envolvendo proteínas, aminoácidos e fenóis, culminando com a formação de pigmentos escuros denominados melaninas, conforme a Figura 3 [5,20,22]. As células de plantas intactas não escurecem por via enzimática porque os fenóis contidos nos vacúolos estão separados das $\mathrm{PFO}$ que estão presentes no citoplasma ${ }^{[21]}$.

O controle do escurecimento enzimático pode ser feito através de métodos físicos e/ou químicos. Métodos químicos envolvem o uso de compostos que inibem a ação da enzima. Alguns químicos já testados com eficácia comprovada na inibição da PFO podem ser prejudiciais ao produto e ao consumidor, trazendo riscos de toxicologia e efeitos sensoriais ao produto ${ }^{[5]}$.

O uso de compostos redutores, como os sulfitos, é efetivo no controle do escurecimento enzimático. Eles previnem o escurecimento através da redução das o-quinonas para o-difenóis, que são compostos menos escuros; ou pela complexação com produtos da reação enzimática formando compostos de 
coloração mais clara e estável ou ainda pela inativação irreversível da PFO [5,22].

O metabissulfito de sódio é utilizado para retardar o processo de escurecimento enzimático na pós-colheita do camarão marinho Litopenaeus vannamei, desde que as concentrações não ultrapassem 100 ppm no produto final cru, evitando assim a ocorrência de melanoses (manchas negras) no produto ${ }^{[8,24]}$. Cardoso et al. [25] em seu estudo sobre a determinação da concentração de sulfito para a manutenção da cor em maçã desidratada constatou que fatias de maçã com adição de metabissulfito acima de $50 \mathrm{mg} / \mathrm{kg}$, mostraram-se eficazes contra o escurecimento. Segundo Machado \& Toledo [3], o escurecimento enzimático é pronunciado em alimentos como batatas, maçãs, cogumelos, bananas, pêssegos, sucos de frutas e vinhos.

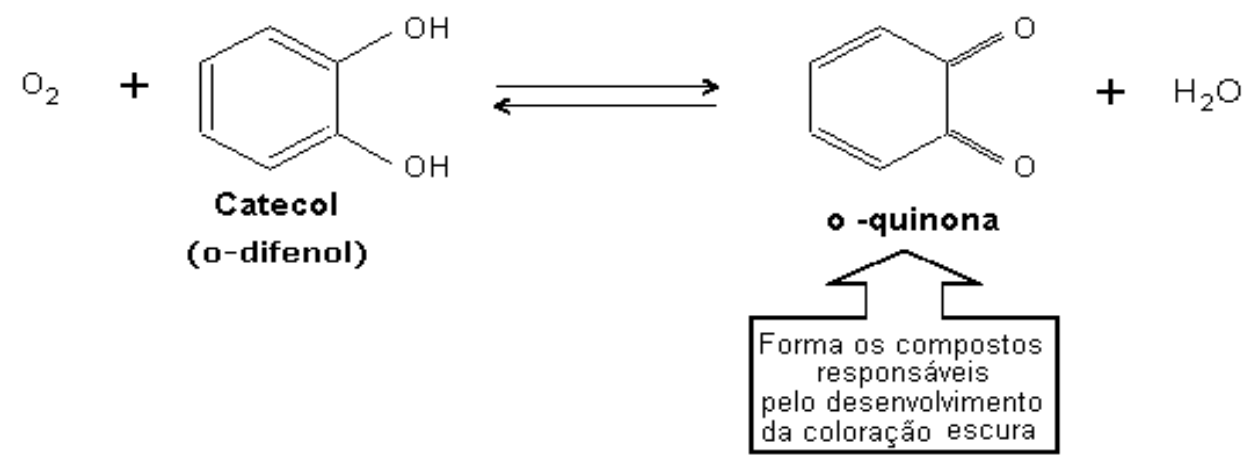

Figura 3. Reação de escurecimento enzimático catalisado pela Polifenoloxidase (PFO) [23].

\section{EFEITOS TÓXICOS E POSSÍVEIS MALEFÍCIOS À POPULAÇÃO CAUSADOS PELOS AGENTES SULFITANTES}

Enquanto os aditivos alimentares não representam riscos para a maioria da população, uma pequena parcela desta pode sofrer com reações adversas causadas por sulfitos ou certos corantes. Importante ressaltar que as reações causadas por sulfitos são caracterizadas como intolerâncias, e não como alergias. A intolerância alimentar pode ter sintomas semelhantes aos de uma alergia (incluindo diarreia, náusea e dor abdominal), mas o sistema imunológico não é envolvido nas reações que ocorrem da mesma maneira. A intolerância alimentar ocorre quando $\mathrm{O}$ organismo não consegue digerir adequadamente um alimento ou um dos seus componentes [26].

As reações adversas aos conservantes, corantes e aditivos alimentares são raras, mas não devem ser menosprezadas. O corante artificial tartrazina, sulfitos e glutamato monossódico são relatados como causadores de reações [12]. Na espécie humana os sulfitos podem provocar anafilaxia, urticária, angioedema, hipotensão, náusea, irritação gástrica local, dores de cabeça, distúrbio do comportamento, erupções cutâneas, diarreia e crise asmática em indivíduos asmáticos sensíveis a sulfitos. A maioria das reações de intolerância adota a forma de ataques asmáticos e urticária. Frequentemente vêm acompanhadas por intolerância ao ácido acetil salicílico. Dependendo da sensibilidade do indivíduo, podem ser induzidas por 2 a $250 \mathrm{mg}$ de dióxido de enxofre, por esta razão, os alimentos que contém sulfitos têm de indicar claramente a presença do mesmo em sua embalagem $[3,4,12,13,27]$.

Segundo a FDA, cerca de 5\% dos asmáticos são sensíveis a sulfitos. Por lei, os agentes sulfitantes, não podem ser pulverizados em vegetais e frutas destinadas a ser consumidas cruas, mas são usados em alguns alimentos processados e para a preservação de frutos do mar. O regulamento da FDA define que os sulfitos devem ser declarados no rótulo quando a quantidade adicionada estiver numa quantidade superior a $10 \mathrm{ppm}$ no produto final [26].

Vários países europeus publicaram estudos, alertando sobre o uso indiscriminado dos agentes sulfitantes, principalmente em alimentos que não 
necessitam de cozimento antes do consumo, como as frutas desidratadas e bebidas alcoólicas. Observou-se, que o consumo desses alimentos e/ou bebidas pode resultar em valores de ingestão de sulfitos acima de sua IDA de $0,7 \mathrm{mg} / \mathrm{kg}$ por peso corpóreo/dia, expressa como $\mathrm{SO}_{2}[3,28]$.

As reações do organismo humano ao dióxido de enxofre variam amplamente. Enquanto algumas pessoas toleram até $4 \mathrm{~g}$ de sulfito diário sem efeitos adversos (ou seja, em torno de $50 \mathrm{mg} / \mathrm{kg}$ de peso corpóreo), outras sofrem dores de cabeça, náuseas, diarreia ou uma sensação de saciedade após comer pequenas quantidades ${ }^{[4,8]}$.

Um fator importante na tolerância do dióxido de enxofre presente nos vinhos é o estado do suco gástrico, de modo que as pessoas com elevada acidez ou então baixa acidez do suco gástrico são consideravelmente mais sensíveis que as pessoas com suco gástrico com acidez normal. Em princípio, o dióxido de enxofre unido ao alimento atua no organismo da mesma maneira que o dióxido de enxofre livre, a diferença depende unicamente da intensidade e rapidez com que começa a reação [4]. Pizzoferrato et al. [10], reforçam a afirmação descrita acima e de acordo com os autores, o sulfito combinado, que reagiu com os constituintes do alimento, quando acidificado e aquecido, in vitro, é liberado sob forma de $\mathrm{SO}_{2}$. Relatam também que estudos posteriores comprovaram que reação semelhante ocorre no trato digestivo, in vivo, sendo necessário quantificar a porção combinada ao alimento (sulfito não livre) para segurança alimentar dos consumidores.

Os dados de intolerância a aditivos alimentares no Brasil são escassos e carecem de metodologia rigorosa. No entanto, apesar de não ser conhecida a prevalência de reações alérgicas a aditivos alimentares no Brasil, estima-se que sua prevalência em países desenvolvidos - comprovada por testes de provocação, varie de 0,01 a $0,23 \%$ [13].

O principal mecanismo de defesa dos mamíferos contra a toxicidade dos sulfitos consiste na oxidação do mesmo a sulfatos a partir da enzima sulfito oxidase, uma hemoproteína que contém molibdênio e se localiza nos espaços intermembranosos das mitocôndrias [3,14]. A deficiência da enzima sulfito oxidase é uma condição autossomal recessiva que se manifesta na infância, ocasionando doenças neurológicas severas e progressivas, dentre elas deslocamento ocular, retardamento mental e crescimento atenuado do cérebro [29,30]. Essa enzima tem maior atividade no fígado, coração e rins, metabolizando e detoxificando os sulfitos ingeridos e o $\mathrm{SO}_{2}$ inalado pelos pulmões, e representando também, a etapa final na conversão de sulfitos de aminoácidos essenciais (cisteína e metionina) a sulfatos, sendo excretado pela urina [7]. Calcula-se que o sulfito endogenamente produzido, em consequência do metabolismo dos compostos sulfurados, supera consideravelmente o consumo exógeno diário com a dieta (em média $6 \mathrm{mg}$ de equivalentes de $\mathrm{SO}_{2}$ por pessoa). Os animais deficientes em sulfito oxidase são mais sensíveis a doses menores de sulfitos. Também são mais sensíveis aos sulfitos, certos pacientes asmáticos, especialmente os submetidos a tratamento com esteróides [3,14].

Em humanos, a intoxicação fatal com dióxido de enxofre é impossível, devido ao fato de provocar vômitos. O dióxido de enxofre e os sulfitos são consideravelmente mais tóxicos quando administrados intravenosamente ${ }^{[4,8]}$.

Os mecanismos pelos quais o dióxido de enxofre produz sintomas que mimetizam alergia estão abertos à discussão. Freedman [31] sugeriu que a ocorrência de sintomas asmáticos, 1 a 2 minutos após a ingestão de bebidas indica que a resposta é devido à inalação de gases ou de rápida absorção através da mucosa bucal. Ele provocou pacientes com $25 \mathrm{~mL}$ de uma mistura aquosa de metabissulfito de sódio e ácido cítrico que rendeu 100 ppm de dióxido de enxofre. Esta concentração é frequentemente encontrada em muitas bebidas a base de laranja na Europa, mas não, por exemplo, nos Estados Unidos. O ar acima dessa mistura tem uma concentração superior a 1 ppm de dióxido de enxofre. Foi demonstrado que a inalação de dióxido de enxofre na concentração de 1 ppm pode causar broncoespasmos em asmáticos. Stevenson \& Simon [32] sugeriram, no entanto, que outros mecanismos estão também envolvidos. Ingestão de encapsulados de metabissulfito de potássio produziram graves sintomas sistêmicos sensíveis em alguns pacientes asmáticos. Os pacientes não mostraram qualquer sinal de sensibilidade imunológica contra metabissulfitos.

Há relato de casos de pacientes asmáticos que sofreram grave asfixia aguda dentro de alguns minutos após ingestão de pequena dose $(5 \mathrm{mg})$ de sulfitos, concluindo os autores que níveis baixos da enzima sulfito-oxidase podem ter contribuído para a sensibilidade aos sulfitos, nos pacientes estudados [33]. 
Contudo, Delohery et al. ${ }^{34]}$ relataram que alguns pacientes sofreram ataque de asma após realizarem "bochechos" com soluções contendo sulfitos, sem ingestão do produto.

Embora os sulfitos, provenientes da produção de vinhos, tenham sido implicados como uma das principais causas da asma existe um número limitado de estudos que comprovem a relação de causalidade. Dessa maneira, Vally \& Thompson [27] realizaram estudos para avaliar a reatividade do sulfito vinícola em asmáticos sensíveis. Sendo que, em apenas um pequeno número de pacientes, foi observada a sensibilidade ao sulfito vinícola, os autores sugerem que o papel dos sulfitos e/ou do vinho em desencadear respostas asmáticas tem sido superestimado, e que mais estudos devem ser implementados para comprovar tal afirmação.

\section{CONCLUSÕES}

Os agentes sulfitantes ainda são muito utilizados na indústria de alimentos como aditivos, responsáveis por controlar o escurecimento enzimático, principalmente em camarões e frutas, destinadas a produção de geleias ou como sucos industrializados, assim como para a inibição do crescimento microbiológico.

Entretanto, reações adversas, como por exemplo - exacerbação da asma em indivíduos asmático sensíveis - vêm sendo associadas a ingestão de sulfitos por essas pessoas. Estudos mostram que pequena parcela da população é sensível a ingestão desse aditivo.

As reações adversas provocadas pelos agentes sulfitantes são relacionadas principalmente à deficiência da enzima sulfito-oxidase, naturalmente presente nos seres humanos, entretanto seus mecanismos não foram totalmente elucidados. Testes mostram que o efeito adverso pode ser provocado pela ingestão do alimento contendo o aditivo, bem como somente sua inalação.

O regulamento da FDA define que os sulfitos devem ser declarados no rótulo quando a quantidade adicionada estiver numa quantidade superior a $10 \mathrm{ppm}$ no produto final. Entretanto, dependendo da sensibilidade do indivíduo, quantidades menores que 10 ppm podem provocar reações adversas.

\section{REFERÊNCIAS}

[1] Polônio MLT, Peres F. Consumo de aditivos alimentares e efeitos à saúde: desafios para a saúde pública brasileira. Cad Saúde Pública. 2009;25(8):1653-666.

[2] Popolim WD. Estimativa da ingestão de sulfitos por escolares pela análise qualitativa da dieta [dissertação]. São Paulo: Universidade de São Paulo; 2004.

[3] Machado RM, Toledo MC. Sulfitos em Alimentos. Braz J Food Technol. 2006;9(4):265-75.

[4] Lück E, Jager M. Conservación química de los alimentos, caracteristicas, usos, efectos. 2o Edición. Zaragoza: Editora Acribia; 1995.

[5] Oliveira TM, Soares NF, Paula CD, Viana GA. Uso de embalagem ativa na inibição do escurecimento enzimático de maçãs. Semina: Ciências Agrárias. 2008;29(1):117-28.

[6] Mcfeeters RF, Barish AO. Sulfite Analysis of Fruits and Vegetables by High-Performance Liquid Chromatography (HPLC) with Ultraviolet Spectrophotometric Detection. J Agric Food Chem. 2003;51(6):1513-517.

[7] Coelho SF. Efeito de diferentes concentrações de conservantes alimentícios no crescimento in vitro de fungos termorresistentes e bactérias patogênicas [dissertação]. Maceió: Universidade Federal de Alagoas; 2008.

[8] Góes LM. Uso do metabissulfito de sódio na pós-colheita do camarão marinho Litopenaeus vannamei [dissertação]. Recife: Universidade Federal Rural de Pernambuco; 2005.

[9] Branen AL, Davidson PM, Salminen S, Thorngaten JH. Food Additives. New York: Marcel Dekker; 2002.

[10] Pizzoferrato L, Di Lullo G, Quattrucci E. Determination of free, bound and total sulphites in foods by indirect photometry-HPLC. Food Chemistry. 1998;63(2):275-79.

[11] Brasil. Agência Nacional de Vigilância Sanitária. Portaria no 540 - SVS/MS de 27 de outubro de 1997. Aprova o Regulamento Técnico: Aditivos Alimentares - definições, classificação e emprego [acesso em 30 jul 2009]. Disponível em: http://www.anvisa.gov.br/legis/portarias/540 97.htm

[12] Scampicchio M, Lawrence NS, Arecchi A, Mannino S. Determination of Sulfite in Wine by Linear Sweep Voltammetry. Electroanalysis. 2008;20(4):444-47.

[13] Pereira AC, Moura SM, Constant PB. Alergia alimentar: sistema imunológico e principais alimentos envolvidos. Semina: Ciências Biológicas e da Saúde. 2008;29(2):189-200.

[14] Wong, DW. Química de los alimentos: Mecanismos y teoria. Zaragoza: Editora Acribia; 1989. 
[15] Brasil. Agência Nacional de Vigilância Sanitária. Resolução da Diretoria Colegiada - RDC no 217, de 29 de julho de 2005 [acesso em 10 set 2009]. Disponível em: http://www.anvisa.gov.br/legis/resol/2005/rdc/217 05rdc. pdf

[16] Brasil. Agência Nacional de Vigilância Sanitária. Resolução do Conselho Nacional de Saúde/Ministério da Saúde, no 04, de 24 de novembro de 1988 [acesso em 12 jun 2009]. Disponível em: http://www.anvisa.gov.br/legis/resol/04 cns.pdf

[17] Edmond LM, Magee EA, Cummings JH. An IEC method for sulphite and sulphate determination in wine without predistillation. LC GC Europe. 2003;6:88-94.

[18] Galvão JF. Sulfitos em bebidas refrigerantes. Boletim do Centro de Pesquisa de Processamento de Alimentos. 1991;9(1):24-9.

[19] Davidson PM, Sofos JN, Branen AL, editors. Antimicrobials in food. Boca Raton: Taylor \& Francis Group; 2005.

[20] Carneiro AA, Alves-Prado HF, Gomes E, Silva R. Escurecimento enzimático em alimentos: Ciclodextrinas como agente antiescurecimento. Alimentos e Nutrição. 2006;17(3):345-52.

[21] Reis FR. Efeito dos processos de branqueamento e acidificação sobre a cor e a absorção de gorduras de batatapalha [dissertação]. Curitiba: Universidade Federal do Paraná; 2007.

[22] Queiroz YS, Bastos DH, Sampaio GR, Soares RA, Ishimoto EY, Torres EA. Influência dos aditivos alimentares na atividade antioxidante in vitro de produtos de alho. Alimentos e Nutrição. 2006;17(3):287-93.

[23] Fennema OR, editor. Food Chemistry. New York: Marcel Dekker; 1996.

[24] Aragão JS, Castro CB, Costa-Lotufo LV. Toxidade do metabissulfito de sódio em Mysidopsis juniae. Arquivo de Ciências do Mar. 2008;41(1):24-9.
[25] Cardoso WS, Pinheiro FA, Patelli T, Perez R, Ramos AM. Determinação da concentração de sulfito para a manutenção da qualidade da cor em maçã desidratada. Revista Analytica. 2007;29:66-72.

[26] Alimentación Sana. Alergias e intolerancias alimentarias [acesso em 25 fev 2011]. Disponível em: http://www.alimentacion-

sana.com.ar/informaciones/novedades/alergias $\% 202 . \mathrm{htm}$

[27] Vally H, Thompson PJ. Role of sulfite additives in wine induced asthma: single dose and cumulative dose studies. Thorax. 2001;56(10):763-69.

[28] World Health Organization. Evaluation of certain food additives. Geneva: WHO Technical Report Series; 2005.

[29] Kisker C, Schindelin H, Pacheco A, Wehbi WA, Garrett RM, Rajagopalan KV, et al. Molecular basis of sulfite oxidase deficiency from the structure of sulfite oxidase. Cell. 1997;91(7):973-83.

[30] Edwards MC, Johnson JL, Marriage B, Graf TN, Coyne $\mathrm{KE}$, Rajagopalan $\mathrm{KV}$, et al. Isolated sulfite oxidase deficiency - review of two cases in one family. Ophthalmology. 1999;106(10):1957-61.

[31] Freedman BJ. A dietary free from additives in the management of allergic disease. Clin Allergy. 1977;7(5):41721.

[32] Stevenson DD, Simon RA. Sensitivity to ingested metabisulfates in asthma subjects. J Allergy Clin Immunol. 1981;68(1):26-32.

[33] Mathison DA, Stevenson DD, Simon RA. Precipitating Factors in Asthma Aspirin, Sulfites, and Other Drugs and Chemical. Chest. 1985;87:50-4.

[34] Delohery J, Castle W, Simmulk K, Allen D. Metabisulfite and $\mathrm{SO}_{2}$, reactivity in asthmatics. J Allergy Clin Immunol. 1984;75:136-41. 